\title{
DIVULGAÇÃO DE INFORMAÇÕES FINANCEIRAS DE COMPANHIAS SIDERÚRGICAS E METALÚRGICAS BRASILEIRAS
}

\section{DISCLOSURE OF FINANCIAL COMPANIES AND STEEL BRAZILIAN METALS}

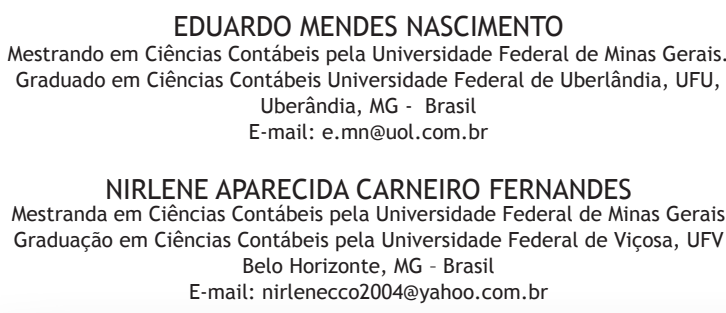

MARIANA GUERRA

Mestre em Ciências Contábeis pela Universidade Federal de Minas Gerais

Analista Financeiro do Centro de Telessaúde do Hospital das Clínicas da UFMG Belo Horizonte, MG - Brasil

E-mail: mariguerra_mg@yahoo.com.br

ROMUALDO DOUGLAS COLAUTO

Professor da Universidade Federal do Paraná, UFPR

Doutor em Engenharia de Produção: gestão de negócios pela Universidade Federal de Santa Catarina, UFSC Curitiba,PR - Brasil

E-mail: rdcolauto@face.ufmg.br

\section{RESUMO}

Informações relevantes, confiáveis e comparáveis podem influenciar o processo decisório. Entretanto, há dificuldade na definição de critérios que possibilitem classificar e diferenciar o nível de disclosure das empresas de forma geral. Nesse sentido, o objetivo deste estudo consiste em analisar o nível de divulgação de informações financeiras de companhias brasileiras do subsetor de siderurgia e metalurgia da BOVESPA. Para tanto, utilizou-se o aporte teórico proposto por Hendriksen e Van Breda (1999) sobre os níveis de divulgação das informações: adequado, justo e completo. Como novidade em relação a diversos outros trabalhos já realizados nesta temática, o estudo propõe um conjunto de critérios que ajudam a tornar o processo de classificação dos níveis de divulgação mais pragmático. A análise considerou a quantidade das informações reportadas no ano de 2008 , sendo a pesquisa caracterizada como descritiva. Os resultados mostram que das 17 companhias que compuseram a amostra, apenas a Usiminas obteve índice suficiente para ser considerada no Nível Justo. Os achados denotam incipiente preocupação das companhias em divulgar as informações obrigatórias. Isto pode ser decorrente imaturidade do mercado acionário brasileiro, ou por refletir que o mercado tem maior preocupação com outras informações econômicas que não são capturadas no financial reporting.

Palavras-chave: Nível de Divulgação. Critérios de Análise. Siderurgia e Metalurgia.

\section{ABSTRACT}

Relevant, reliable and comparable information can influence the decision making process. However, there is difficulty in defining criteria to classify and differentiate the level of disclosure of companies in general. Thus, the purpose of this study is to examine the level of financial disclosure of Brazilian companies in the subsector of steel and metallurgy listed on BOVESPA. To do this, we used the theoretical framework proposed by Hendriksen and Van Breda (1999) on the levels of information disclosure: adequate, fair and complete. As a novelty in relation to various other works developed on this subject, the study proposes a set of criteria that help making the process of disclosure levels classification more pragmatic. The analysis considered the amount of information reported in 2008 and the study is characterized as descriptive. The results show that from the 17 companies that comprised the sample, only Usiminas gained enough to be considered at Fair Level. The findings denote incipient concern of companies for disclosing the required information. This may be due to immaturity of Brazilian stock market, or to a reflection that the market is more concerned with other economic information that is not captured in financial reporting.

Key-words: Level of Disclosure. Review Criteria. Steel \& Metallurgy. 


\section{INTRODUÇÃO}

A importância da divulgação de informações financeiras que auxiliam no processo decisório tem sido cada vez mais debatida no meio acadêmico (HOPE, 2003; LANZANA, 2004). Diversos trabalhos destacam a transparência nas informações divulgadas como um fator essencial no momento de se decidir sobre os investimentos em companhias (GONÇALVES et al., 2007). Vasconcelos e Viana (2002) explicam que os usuários precisam compreender a essência da informação para atribuir valor e melhorar o processo de tomada de decisão e, para isso, a informação deve ser clara, objetiva e tempestiva. A política de divulgação é fundamental para que a Contabilidade atenda seus objetivos de gerar informações para todos os seus usuários, não restringindo apenas a publicação das demonstrações contábeis obrigatórias, mas também a outros aspectos relativos à companhia que possam influenciar na tomada de decisão (LOPES; MARTINS, 2007). Consequentemente, faz-se necessário o estabelecimento de critérios de divulgação a fim de garantir a disponibilização de um conjunto mínimo de informações que atendam aos interesses dos diversos grupos de usuários.

Em relação à divulgação de informações obrigatórias (compulsórias), há regulamentações específicas para os diferentes setores do mercado. Por meio destas, busca-se garantir a maior confiabilidade e padronização das informações divulgadas, a fim de assegurar que as necessidades informacionais dos usuários investidores sejam atendidas (GONÇALVES; OTT, 2002). Entretanto, quando se refere às informações divulgadas de forma voluntária (não compulsória), não há regulamentação ou padrões pré-estabelecidos que garantam a confiabilidade das informações. Nesse sentido, a Comissão de Valores Mobiliários (CVM), por meio do Parecer 15/87, orienta sobre os itens e demonstrativos recomendados na forma de divulgação voluntária.

Considerando-se as necessidades informacionais dos diferentes usuários, bem como o elevado número de transações realizadas atualmente no mercado de ações, parece pertinente mencionar que todas as informações que possam interferir ou influenciar no processo de tomada de decisões racionais devam ser divulgadas aos interessados (FERREIRA; BOTELHO, 2006). Segundo Lopes e Martins (2007), a observação das características específicas da informação contábil é essencial para que ela seja útil para os usuários em termos de Relevância, Confiabilidade e Comparabilidade.

A Informação Relevante é aquela que afeta o processo decisório, devendo ser confiável ou livre de viés e deve ser comparável em momentos econômicos diferentes. Os Pareceres de Orientação da CVM e os Pronunciamentos de Entidades Nacionais e Internacionais Regulamentadoras da Contabilidade objetivam definir quais informações são consideradas importantes e podem interferir ou influenciar no processo decisório. A Informação Confiável deve ser neutra e proporcionar uma representação fiel dos eventos (FERREIRA; BOTELHO, 2006). Para Gonçalves e Ott (2002) a Confiabilidade é a qualidade que dá convicção de que a informação está razoavelmente livre de erro e de inclinação, e representa o que pretende representar. A comparabilidade, por sua vez, é a característica que oferece condições para a identificação de uma tendência e para análise da evolução dos valores apresentados pela Contabilidade (GOULART, 
2003). Dessa forma, a Informação Comparável possibilita a análise de uma mesma companhia em diferentes períodos, e entre companhias distintas.

Considerando as características específicas da informação contábil, o objetivo do presente estudo é analisar o nível de divulgação de informações das companhias brasileiras do subsetor de siderurgia e metalurgia que negociam ações na BOVESPA. Para tanto, utiliza-se o referencial proposto por Hendriksen e Van Breda (1999) sobre a classificação das informações divulgadas. O presente artigo está estruturado em cinco seções, incluindo esta introdução. Primeiramente, apresentase o referencial teórico sobre os níveis de divulgação e sobre os principais grupos de usuários da Contabilidade e suas necessidades informacionais. A seguir, apresentase a metodologia da pesquisa e demonstra-se a análise do nível de divulgação das companhias classificadas no subsetor de siderurgia e metalurgia da BOVESPA. Por fim, apresentam-se as considerações finais do trabalho e recomendações para futuros trabalhos.

\section{REFERENCIAL TEÓRICO}

\subsection{NÍVEIS DE DIVULGAÇÃO DA INFORMAÇÃO CONTÁBIL}

A abertura de informações pelas companhias em um contexto global tem sido ainda mais enfocada nos últimos anos, dada a globalização do mercado de capitais e a busca de uma harmonização das práticas contábeis (HO; TAYLOR, 2007). Conforme Lanzana (2004), no contexto de mercados emergentes, a questão da abertura voluntária de informações é ainda mais crítica, já que a legislação em geral é menos rígida, além do fato de que certas características das companhias destes mercados, com alta concentração acionária e fortes traços culturais, causam maior insegurança para os investidores em geral.

Segundo Healy e Palepu (2001) há diversas teorias para explicar o nível de disclosure das companhias, sendo que essas podem ser separadas em algumas abordagens, quais sejam: (a) o papel do disclosure para o mercado de capitais; (b) a regulação relacionada ao disclosure; (c) o papel dos auditores e intermediários no processo de disclosure; (d) fatores relacionados às decisões de disclosure; e, (e) consequências das decisões de disclosure. Dentre essas, destaca-se a última abordagem, que busca explicar as variáveis que influenciam no nível de disclosure das companhias. Aliado a essas variáveis, alguns fatores informacionais possibilitam diferenciar os níveis e formas de divulgação de informações das companhias. Entretanto, a fim de garantir a satisfação das necessidades dos usuários da Contabilidade, devese divulgar informações em quantidade e qualidade que podem oferecer suporte e influenciar as decisões de investimentos (GONÇALVES; OTT, 2002).

Yamamoto e Salotti (2006) mencionam que o modo como o disclosure deve ser tratado, se voluntário ou obrigatório, requer análises acuradas. Para tanto, é necessário considerar os benefícios da divulgação de informações obrigatórias, os quais podem ser exemplificados pelo entendimento de investidores e demais usuários da Contabilidade de que a companhia está cumprindo a determinação de divulgar 
as informações compulsórias. Por outro lado, argumenta-se que as companhias, ao evidenciarem apenas informações obrigatórias podem não suprir de forma suficiente às necessidades informacionais de alguns usuários, sendo considerado também importante que as companhias divulguem informações voluntárias. A evidenciação de itens não obrigatórios, entretanto, poder levar a ocorrência de certas despesas extras. Dessa forma, tem-se que as companhias possuem certos estímulos necessários à divulgação de informações voluntárias com vistas a satisfazer seus investidores, mas que, por outro lado, podem ser suficientes para justificar o custo/benefício dessa evidenciação (HEALY; PALEPU, 2001).

A fim de esclarecer como as informações devem ser divulgadas, Hendriksen e Van Breda (1999) definem três níveis: (I) adequado; (II) justo (fair disclosure) e (III) completo (full disclosure). A divulgação considerada Adequada requer um volume mínimo de informações compatíveis com o objetivo de evitar que as demonstrações sejam superficiais; Justa (fair disclosure), os objetivos éticos de tratamento equitativo de todos os usuários em potencial sejam observados; e Completa (full disclosure) que apresenta informações relevantes para os diversos grupos de usuários.

A classificação da divulgação de informações de acordo com esses níveis propostos por Hendriken e Van Breda (1999) perpassa a discussão de alcance dos objetivos da Contabilidade. Ferreira e Botelho (2006), considerando as necessidades informacionais dos diferentes usuários da informação, afirmam que a informação deve oferecer suporte ao processo decisório de forma racional. Assim, precisa ser adaptada a cada grupo de interesses para que possa ser útil, mesmo que não atenda a todos os interesses individuais (BRISOLA, 2004). Apesar disto, presume-se que as informações divulgadas para investidores e acionistas sejam também suficientes para os demais grupos de usuários. Esse pressuposto está relacionado ao desconhecimento das reais necessidades informacionais dos diferentes usuários da Contabilidade. Por esse motivo, entende-se que a divulgação para investidores e credores, dada a sua abrangência e complexidade, também atendam aos demais usuários (HENDRIKSEN; VAN BREDA, 1999).

A discussão do alcance dos objetivos da Contabilidade traz à tona a necessidade de divulgação de informações compulsórias e voluntárias bem como a adequação dos principais métodos de divulgação. Esses métodos não se resumem apenas nas demonstrações contábeis propriamente ditas, mas incluem a divulgação de informações relevantes por meio das Notas Explicativas (NE), Relatório da Administração (RA), Quadros Complementares e Parecer de Auditoria (GONÇALVES; OTT, 2002, GRAHAM; HARVEY; RAJGOPAL, 2005). Hendriksen e Van Breda (1999) destacam que as NE e o RA apresentam menor padronização e regulamentação do que as demonstrações contábeis propriamente ditas, devido à amplitude das informações qualitativas e discursivas que podem evidenciar.

Para Ponte et al. (2007), a escolha do melhor método de divulgação contábil depende da natureza da informação e de sua importância relativa. Nesse sentido, destacam-se a flexibilidade das NE e do RA em função da amplitude das informações que podem ser divulgadas, incluindo as voluntárias. A relevância das NE pode também ser notada no art. 176 da Lei 6.404/76 ao determinar que as demonstrações contábeis sejam necessariamente acompanhadas por NE e outros quadros analíticos necessários aos esclarecimentos da situação patrimonial e do resultado do exercício. 
Aliada às exigências da Lei 6.404/76, a CVM orienta a apresentação em NE de diversas informações necessárias ao esclarecimento e análise da situação e dos resultados contábeis. E ainda determina a publicação do RA no encerramento do exercício social. No RA, devem ser apresentadas informações, principalmente, sobre: (a) aquisição de debêntures de sua própria emissão; (b) política de reinvestimento de lucros e distribuiçãa de dividendos constantes no acordo de acionistas; (c) negócios sociais e principais fatos administrativos ocorridos no exercício; e (d) relação dos investimentos em sociedades coligadas e/ou controladas evidenciando as modificações ocorridas durante o exercício.

\subsection{PRINCIPAIS GRUPOS DE USUÁRIOS DA CONTABILIDADE E SUAS NECESSIDADES INFORMACIONAIS}

Em relação às formas de avaliar os níveis de divulgação, destaca-se o trabalho de Michelon (2007, apud ALVES; LIMA, 2008). Ao criar um índice de disclosure, Michelon (2007) identificou quatro categorias básicas de informação: (i) estratégica; (ii) financeira; (iii) ambiental; e, (iv) social. De acordo com essas categorias o disclosure de informações estratégicas engloba a evidenciação de metas e objetivos da companhia, estratégias do negócio, modelo de governança, principais produtos, ambiente competitivo e principais mercados de atuação, consubstanciadas em informações econômicas e financeiras. As informações ambientais compreendem a evidenciação do impacto ambiental e as políticas voltadas a preservação do meio ambiente. As sociais envolvem a divulgação de aspectos de atuação social da companhia, tais como práticas trabalhistas, direitos humanos e responsabilidade do produto. A elaboração do Índice de Disclosure de Michelon (2007) teve a finalidade de avaliar a atenção dada às necessidades informacionais dos diferentes usuários.

Para o cálculo do nível de divulgação, de acordo Hendriksen e Van Breda (1999), é necessário atentar-se ao fato de que a divulgação requer a consideração das necessidades informacionais dos diferentes usuários e não somente dos investidores e acionistas, em contraposição ao pressuposto de que a satisfação desses usuários possibilita também aos demais grupos as informações necessárias para suas decisões. Assim, para que se estabeleça o nível suficiente de informação a ser divulgado pelas companhias, faz-se necessário definir os usuários que se pretende atingir e reconhecer as diferenças entre os interesses e as necessidades informacionais desses (HIRSHLEIFER; TEOH, 2003).

Por conseguinte, a Contabilidade precisa adaptar a cada categoria as informações que realmente são úteis em seu processo decisório (LOPES; MARTINS, 2007). De acordo com Ferreira e Botelho (2006), deve-se primeiramente definir quais os usuários pretende-se atingir com a divulgação contábil, além de conhecer o ambiente econômico, legal, político e social no qual os padrões de divulgação são fixados. As informações geradas pela companhia devem ser amplas e fidedignas, além de suficientes para a avaliação da situação patrimonial e das mutações sofridas pelo seu patrimônio, permitindo inferências sobre o seu futuro (BUENO, 1999). Para Lopes e Martins (2007, p. 65), "a relevância da informação contábil, do ponto de vista econômico e informacional, reside em sua capacidade de prever fluxos de caixa 
futuros".

Hendriksen e Van Breda (1999) definem 10 grupos de usuários e as respectivas finalidades de informação. Os investidores e acionistas buscam identificar a situação econômico-financeira das companhias e decidir sobre melhores alternativas de investimento. Os credores desejam informações para aprovar empréstimos e limites de créditos por meio da análise das informações das companhias. Os funcionários e sindicados analisam a produtividade do setor, como um fator preponderante para o reajuste de salários. Os fornecedores e clientes verificam a capacidade de pagamento e a manutenção de compromisso das companhias. O Governo e suas agências analisam o índice de arrecadação de impostos e obtêm dados estatísticos (IBGE). As Agências sócio-ambientais observam as mudanças que as companhias operam na sociedade. As Agências Reguladoras do mercado de capitais buscam garantir a eficiência do mercado de ações. Os auditores externos verificam a obediência da Estrutura Conceitual Básica para Elaboração e Apresentação das Demonstrações Contábeis. Os administradores e demais usuários internos que acompanham o resultado para prospecções futuras. Os demais usuários que não foram definidos nos demais grupos têm finalidades diversas.

Acerca do nível de informação disponibilizada, os usuários externos recebem uma parcela menor de informação em relação aos internos, pois os externos limitamse ao que é divulgado pelas companhias, enquanto os internos estão diretamente ligados ao cotidiano da companhia, detendo o privilégio da informação completa e de primeira mão (FERREIRA; BOTELHO, 2006). Além dessas informações obrigatórias, há um conjunto de informações voluntárias que são de interesse de usuários externos, tendo a CVM emitido Parecer $n^{\circ}$ 15/87 recomendando a divulgação de informações, a saber: descrição dos negócios, produtos e serviços; comentários sobre a conjuntura econômica; recursos humanos; investimentos; P\&D; novos produtos e serviços; proteção ao meio ambiente; reformulações administrativas dentre outras. A divulgação de informações voluntárias, de certa forma, pode estar condicionada a alguns motivos, tais como: o tamanho (LANZANA, 2004), o desempenho da companhia e a internacionalização (SALOTTI; YAMAMOTO, 2006).

\subsection{PESQUISAS RELACIONADAS}

ODisclosure de informações faculta uma avaliação dos investimentos de maneira mais exata, o que, de certa forma, alocaria os recursos escassos de maneira mais eficaz, conforme Alencar (2007). Buscando essa comprovação, Murcia e Santos (2009) fizeram uma análise de conteúdo nas demonstrações contábeis das 100 maiores empresas que negociavam ação na BM\&F Bovespa do ano de 2007 com o fim de analisar as práticas de disclosure voluntário. Os autores constataram que entre as 06 categorias analisadas (totalizando 43 subcategorias) há uma grande variação entre essas empresas. Verificou-se, assim, um grupo com tendência a promover uma forte divulgação de informações voluntárias e outro que se restringe a publicar as demonstrações obrigatórias. Detalhadamente, observa-se que as empresas que mais divulgam informações voluntariamente são as que possuem maior valor de mercado (Petrobrás; Usiminas; Eletrobrás; CSN e Vale). 
Ainda sobre o nível de divulgação, Al-Shammari (2005) estudou 137 empresas com sede nos países que compunham o Conselho de Cooperação do Golfo no período de 1996 a 2002. O autor constatou que nenhuma das empresas estava plenamente em conformidade com as divulgações obrigatórias. Todavia, o autor observou que o nível médio de adequação evoluiu de 68\% em 1996 para 82\% em 2002. Para Al-Shammari (2005), um maior nível de divulgação encontra-se nas empresas com maior tamanho, alto grau de alavancagem e internacionalizadas.

As informações contábeis, sobretudo as voluntárias, possibilitam uma diminuição do custo de capital para as empresas, na medida em que conseguem mitigar a assimetria informacional entre os agentes, conforme comprova Lima (2007). Esse autor fez uma análise de regressão com dados em painel nas demonstrações dos períodos de 2000 a 2004 de 23 empresas. O autor constatou que para as empresas analisadas o custo de capital possui uma relação inversa com o disclosure voluntário, ou seja, quanto maior o disclosure, menor o custo de capital. Diversamente do que concluiu, Mazer (2007), mencionado anteriormente, segundo o qual, para as empresas que compunham o índice Bovespa, não se podia estabelecer uma relação entre o nível de divulgação contábil publicada e o custo de capital.

No Brasil, apesar de haver recomendações de órgãos como a CVM no sentido de incentivar que as empresas divulguem voluntariamente informações relevantes para o mercado, as exigências são menores em comparação aos Estados Unidos. 0 estudo anteriores, de Ponte e Oliveira (2004) e Ponte et al. (2007) revelou que as empresas brasileiras apresentam baixo índice de evidenciação de informações não obrigatórias.

\section{METODOLOGIA}

A pesquisa caracteriza-se como descritiva com abordagem predominantemente qualitativa e foi desenvolvida em quatro etapas com o objetivo de elaborar critérios para classificar o nível de divulgação de informações financeiras de companhias brasileiras com ações negociadas em bolsa de valores. A justificativa para escolha da pesquisa descritiva com abordagem qualitativa consubstancia-se no fato de o estudo selecionar questões acerca das necessidades informacionais para cada tipologia de usuário da Contabilidade e após, coletar informações sobre cada uma delas, para assim, descrever o nível de evidenciação das informações de companhias brasileiras (SAMPIERI; COLLADO; LUCIO, 2006).

Para formação do corpo teórico, utiliza-se a plataforma teórica de Hendriksen e Van Breda (1999) que classificaram os níveis de divulgação em (a) adequado; (b) justo e (c) completo. Os autores argumentam que para cada um dos níveis de divulgação deve haver um delineamento das informações a serem divulgadas para satisfação das expectativas dos usuários da Contabilidade. A proposta de classificação dos níveis de divulgação de Hendriksen e Van Breda (1999) tem uma conotação de hierarquização em relação à quantidade e qualidade das informações divulgadas pelas companhias. Nesse raciocínio, parece pertinente que o nível de divulgação migre, sequencialmente, de adequado para justo e após para completo. 
De acordo com o nível de divulgação há enfoques diferenciados em relação à quantidade e qualidade das informações divulgadas. No nível adequado, o enfoque da divulgação recai sobre as informações obrigatórias (compulsórias). No nível justo, além das informações adequadas, a divulgação precisa atender as necessidades informacionais de grupos de usuários distintos, tais como: investidores, credores, funcionários e governo. No nível completo, além das informações adequadas e justas, faz-se necessário contemplar as informações voluntárias (não obrigatórias).

Em relação aos procedimentos operacionais da pesquisa, na primeira etapa, realizou-se uma revisão da literatura sobre trabalhos acerca da evidenciação em companhias que mantêm ações negociadas na BOVESPA. A revisão bibliográfica centrou-se na compreensão das informações obrigatórias e voluntárias divulgadas nas NE e nos RA das companhias de capital aberto para todas as tipologias de usuários. Também foram verificados, nos pareceres da CVM, as informações que devem ser divulgadas de acordo com os aspectos normativos brasileiros, bem como, as sugestões de divulgação adicional para melhorar a qualidade do financial reporting.

$\mathrm{Na}$ segunda etapa da pesquisa, foram coletados as NE e os RA de companhias brasileiras classificadas no subsetor de siderurgia e metalurgia da BOVESPA referentes ao ano de 2008. A restrição ao ano de 2008 deve-se ao fato de que anteriormente as companhias estavam desobrigadas a divulgar algumas das demonstrações contábeis, como a Demonstração de Valor Adicionado e a Demonstração de Fluxos de Caixa. Portanto, o objetivo dessa etapa foi verificar as principais informações obrigatórias e voluntárias divulgadas especificamente no subsetor de siderurgia e metalurgia. Para tanto, utilizou-se a Análise de Conteúdo.

A Análise de Conteúdo, segundo Bardin (2002), pode ser definida como um conjunto de técnicas de análise das comunicações visando obter, por procedimentos sistemáticos e objetivos de descrição do conteúdo das mensagens, indicadores que possibilitam a inferência de conhecimentos relativos às condições de produção/ recepção destas mensagens. O processo de Análise de Conteúdo envolve três procedimentos sequenciais: (i) pré-análise; (ii) exploração do material; e (iii) tratamento dos resultados, inferência e interpretação.

Nos procedimentos de pré-análise foram mapeadas as informações dispostas nas NE e nos RA que possibilitam classificá-las nos três níveis de divulgação propostos por Hendriksen e Van Breda (1999). Após identificou-se o teor do conteúdo disponibilizado nesses documentos, ou seja, buscou-se compreender a natureza das informações financeiras, contábeis e econômicas. Para tratamento dos resultados, interpretação e apresentação das inferências classificou-se as informações levantadas em: obrigatórias (adequada); específicas para determinados usuários (adequada + justa); e voluntárias (adequada + justa + completa).

Para realização da terceira etapa, foi necessário definir um parâmetro de comparação para classificar as informações divulgadas nas NE e nos RA em: Informações obrigatórias e Informações Voluntárias, conforme apresentado nos Quadros 1 e 2. As informações obrigatórias listadas no Quadro 1 referem-se ao mínimo de informações estabelecidas como necessárias e que atendam aos interesses dos diversos grupos de usuários, conforme determinação disposta nos Pareceres de Orientação da CVM e na Lei $6.404 / 76$. Dentre as informações compulsórias, destaca-se a necessidade de 
apresentação de itens especificamente em NE, tais como: arrendamento mercantil; dividendo por ação; e outras informações que são requeridas obrigatoriamente no RA, como a relação dos investimentos em sociedades em que a companhia tem participação (coligadas e/ou controladas).

\begin{tabular}{|c|c|}
\hline \multicolumn{2}{|c|}{ Notas Explicativas } \\
\hline Ações em tesouraria & Obrigações de longo prazo \\
\hline Ajustes de exercícios anteriores & Ônus, garantias e responsabilidades \\
\hline Arrendamento mercantil & Opções de compra de ações \\
\hline Capital autorizado & Mudança de critério contábil \\
\hline Capital social & Obrigações de longo prazo \\
\hline Critérios de avaliação & Ônus, garantias e responsabilidades \\
\hline Demonstrações consolidadas & Opções de compra de ações \\
\hline Dividendo por ação & Remuneração dos administradores \\
\hline Equivalência patrimonial & Reservas \\
\hline Eventos subseqüentes & Reserva de lucros realizada e a realizar \\
\hline Impostos e operações de câmbio & Retenção de lucro \\
\hline Investimentos societários no exterior & Transações entre partes relacionadas \\
\hline \multicolumn{2}{|l|}{ Mudança de critério contábil } \\
\hline \multicolumn{2}{|c|}{ Relatório da Administração } \\
\hline $\begin{array}{c}\text { Aquisição de debêntures de própria } \\
\text { emissão }\end{array}$ & $\begin{array}{c}\text { Relação dos investimentos em sociedades } \\
\text { coligadas e/ou controladas e as modificações } \\
\text { ocorridas durante o exercício }\end{array}$ \\
\hline $\begin{array}{l}\text { Política de reinvestimento de lucros e } \\
\text { distribuição de dividendos }\end{array}$ & $\begin{array}{l}\text { Negócios sociais e principais fatos } \\
\text { administrativos ocorridos no exercício }\end{array}$ \\
\hline
\end{tabular}

Quadro 1: Parâmetro de divulgação de informações nas NE e nos RA

Fonte: elaborado pelos autores

Além das informações compulsórias, no Quadro 2 apresentam-se os itens voluntários que podem ser apresentados nas NE e no RA, conforme Parecer de Orientação da CVM. A subdivisão das informações voluntárias em informações destinadas a usuários específicos e informações adicionais busca estabelecer um critério para situá-las nos níveis de divulgação justa e completa. Além disso, a base para sustentação do parâmetro de divulgação de informações financeiras encontra respaldo a partir das informações consideradas pertinentes de divulgação segundo as diversas publicações científicas no Brasil e Exterior, Pareceres da CVM (etapa 1 da pesquisa descritiva), além de arquétipos de disclosure verificados nas NE e nos RA das companhias classificadas no subsetor de siderurgia e metalurgia BOVESPA (etapa 2 da pesquisa descritiva).

$\mathrm{Na}$ quarta etapa do estudo, foram delineados os critérios qualitativos para subsidiar o processo de coleta de evidências para análise dos níveis de divulgação como apresentado no Quadro 3. Os níveis de evidenciação estão segmentados em três graus de divulgação com a finalidade de diferenciar as companhias que evidenciam em maior ou menor completude as informações para situá-las nos níveis adequado, justo e completo. 
Com base nesses critérios, as divulgações das companhias podem ser enquadradas no nível adequado e Grau 1 quando as informações obrigatórias forem incipientes; no Grau 2, quando essas informações forem parciais; e para se enquadrar no Grau 3 , as informações obrigatórias devem ser amplamente divulgadas e auditadas. Para o nível justo, as companhias são segmentadas no Grau 1, quando a divulgação tiver foco apenas no grupo de usuários investidores; no Grau 2, se o foco das informações for em mais de um grupo usuário; e no Grau 3 se as informações divulgadas tiverem foco em vários grupos de usuários. No nível completo de Grau 1, classificam-se as companhias que divulgarem informações voluntárias de forma incipiente; se as informações forem divulgadas parcialmente, a classificação é no Grau 2; e no Grau 3 se as companhias divulgarem amplamente as informações voluntárias.

\begin{tabular}{|c|c|c|}
\hline & \multicolumn{2}{|c|}{ Informações Voluntárias } \\
\hline & Destinadas a usuários específicos & Adicionais \\
\hline \multirow{6}{*}{ 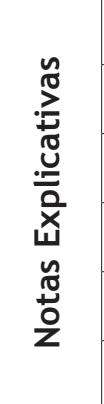 } & Balanço social & Maior ênfase nas demonstrações consolidadas \\
\hline & Número de empregados, turnover & Comentários sobre a conjuntura econômica \\
\hline & Projetos sociais & $\begin{array}{l}\text { Descrição sucinta de projetos de P\&D e dos recursos } \\
\text { alocados nesses }\end{array}$ \\
\hline & $\begin{array}{l}\text { Relatório sobre ações judiciais } \\
\text { importantes }\end{array}$ & Descrição dos negócios da companhia \\
\hline & $\begin{array}{l}\text { Dividendos propostos pela } \\
\text { Administraçao }\end{array}$ & $\begin{array}{l}\text { Resultados por linha de produtos ou segmentos de } \\
\text { negocios }\end{array}$ \\
\hline & & Nota sobre Ativos Segurados \\
\hline \multirow{7}{*}{ 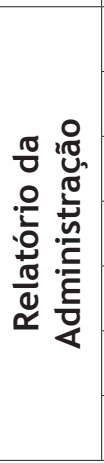 } & $\begin{array}{l}\text { Descricião de reorganizaçãa } \\
\text { societâria }\end{array}$ & Descrição de novos produtos e as expectativas \\
\hline & $\begin{array}{l}\text { Informacõos sobre Recursos } \\
\text { Humanos }\end{array}$ & $\begin{array}{l}\text { Discussão e análise da situação financeira e dos } \\
\text { resultados operacionais pelá Administração }\end{array}$ \\
\hline & & Descrição e objetivos dos investimentos \\
\hline & & Mercado de ações da companhia \\
\hline & & $\begin{array}{l}\text { Perspectivas e planos para o exercício em curso e os } \\
\text { futuros }\end{array}$ \\
\hline & & Proteção ao meio-ambiente \\
\hline & & $\begin{array}{l}\text { Descrição sucinta dos projetos, recursos alocados, } \\
\text { montantes aplicados e situação dos projetos }\end{array}$ \\
\hline
\end{tabular}

Quadro 2: Parâmetro de divulgação de informações financeiras nas NE e nos RA

Fonte: elaborado pelos autores.

A fim de verificar se informações divulgadas atendem às exigências para os níveis adequado, justo e completo, utilizam-se métricas quantitativas, analisadas por meio de uma Escala Likert de 3 pontos, como apresentado no Quadro 4. As métricas quantitativas objetivam diferenciar as companhias que reportam em maior ou menor completude as informações. Dessa forma, de acordo com os parâmetros de comparação apresentados nos Quadros 1 e 2, espera-se quantificar quais as informações listadas são efetivamente divulgadas pelas companhias. Essa quantificação é apresentada em forma percentual (Quadro 4), na razão da quantidade de informação divulgada e a quantidade definida no parâmetro de comparação.

Com isto, a companhia poderá ser classificada no Grau 1 de cada nível estabelecido se as informações divulgadas atingirem o percentual de 0 a $40 \%$ do parâmetro definido de acordo com o tipo de informação; no grau 2 se atingirem o percentual de 41 a $80 \%$; e no grau 3 se atingirem o percentual de 81 a $100 \%$ das 
informações divulgadas segundo o parâmetro de comparação.

Entende-se que a utilização da Escala Likert de 3 pontos é adequada para diferenciar as companhias que se encontram em determinado nível de divulgação. Assim, as companhias A e B, por exemplo, podem ser classificadas no nível adequado, mas deverão ser diferenciadas pela quantidade de informações que divulgam. Essa diferenciação é necessária para melhor identificação e comparação das diferentes companhias analisadas.

\begin{tabular}{|c|c|l|}
\hline $\begin{array}{c}\text { Nivel de } \\
\text { divulgação }\end{array}$ & $\begin{array}{c}\text { Grau de } \\
\text { divulgação }\end{array}$ & \multicolumn{1}{c|}{ Critérios qualitativos } \\
\hline \multirow{3}{*}{ Adequado } & 1 & Informações obrigatórias incipientemente divulgadas \\
\cline { 2 - 3 } & 2 & Informações obrigatórias divulgadas parcialmente \\
\cline { 2 - 3 } & 3 & Informações obrigatórias amplamente divulgadas e auditadas \\
\hline \multirow{3}{*}{ Justo } & 1 & Evidenciação adequada com foco apenas no usuário investidor \\
\cline { 2 - 4 } & 2 & Evidenciação adequada com foco em mais de um grupo de usuários \\
\hline \multirow{3}{*}{ Completo } & 3 & Evidenciação adequada com foco em vários grupos de usuários \\
\cline { 2 - 3 } & 1 & $\begin{array}{l}\text { Evidenciação justa e informações voluntárias incipientemente } \\
\text { divulgadaś }\end{array}$ \\
\cline { 2 - 3 } & 2 & $\begin{array}{l}\text { Evidenciação justa e informações voluntárias divulgadas } \\
\text { parcialmeñte }\end{array}$ \\
\cline { 2 - 3 } & 3 & Evidenciação justa e todas as informações voluntárias divulgadas \\
\hline
\end{tabular}

Quadro 3: Critérios qualitativos para classificação dos níveis e graus de divulgação de informações nas NE e nos RA

Fonte: elaborado pelos autores.

\begin{tabular}{|c|c|l|}
\hline Nível de divulgação & Grau de divulgação & \multicolumn{1}{c|}{ Escala Likert } \\
\hline \multirow{3}{*}{ Adequado } & 1 & 0 a 40\% das informações \\
\cline { 2 - 3 } & 2 & 41 a $80 \%$ das informações \\
\cline { 2 - 3 } & 3 & 81 a $100 \%$ das informações \\
\hline \multirow{3}{*}{ Justo } & 1 & 0 a 40\% das informações \\
\cline { 2 - 3 } & 2 & 41 a $80 \%$ das informações \\
\hline \multirow{3}{*}{ Completo } & 3 & 81 a $100 \%$ das informações \\
\cline { 2 - 3 } & 1 & 41 a $80 \%$ das informações \\
\cline { 2 - 3 } & 2 & 81 a $100 \%$ das informações \\
\hline
\end{tabular}

Quadro 4: Escala Likert para mensuração dos níveis e dos graus de divulgação

Fonte: elaborado pelos autores.

\section{ANÁLISE DO NÍVEL DE DIVULGAÇÃO}

\subsection{CARACTERIZAÇÃO DA AMOSTRA}

A amostra de 17 companhias do subsetor siderurgia e metalurgia foi selecionada de forma intencional: Aços Villares, Aliperti, Caraíba, CONFAB, CSN, Duque, ELUMA, FERBASA, FIBAM, Gerdau, Gerdau Metalúrgica, Mangels, Panatlântica, Paranapanema, Tekno, Usiminas e Vicunha. A escolha deste subsetor deve-se ao fato de comportar companhias que poderiam apresentar certa variabilidade de informações divulgadas 
nas NE e no RA, tanto no que se referem aos itens obrigatórios, quanto aos voluntários. Isso porque no subsetor siderurgia e metalurgia da BOVESPA estão listadas importantes holdings brasileiras e companhias de grande e médio porte, com um volume de transações significativo e relativa representatividade na economia nacional. Dada a significância econômico-financeira desse conjunto de companhias para o país a amostra tem condições de exemplificar adequadamente os diferentes critérios qualitativos definidos para avaliação do nível de disclosure.

\subsection{DESCRIÇÃO E ANÁLISE DOS DADOS A PARTIR DOS CRITÉRIOS QUALITATIVOS}

Inicialmente realizou-se a Análise do Conteúdo nas NE e nos RA a fim de comparar com os parâmetros estabelecidos nos Quadros 2 e 3. No que se refere às informações obrigatórias divulgadas nas NE pelas companhias, apresentam-se na Tabela 1 as frequências absoluta (fi) e relativa (fi\%) de cada item obrigatório. No decorrer da análise busca-se inferir sobre a divulgação ou não de determinadas informações obrigatórias.

Tabela 1: Informações obrigatórias divulgadas nas NE

\begin{tabular}{|lc|c|}
\hline \multicolumn{1}{|c|}{ Informações Obrigatórias nas NE } & $\mathrm{fi}$ & $\mathrm{fi} \%$ \\
\hline Capital social & 17 & $100,00 \%$ \\
\hline Critérios de avaliação & 17 & $100,00 \%$ \\
\hline Mudança de critério contábil & 16 & $94,12 \%$ \\
\hline Demonstrações consolidadas & 15 & $88,24 \%$ \\
\hline Reservas & 15 & $88,24 \%$ \\
\hline Impostos e operações de câmbio & 14 & $82,35 \%$ \\
\hline Obrigações de longo prazo & 14 & $82,35 \%$ \\
\hline Transações entre partes relacionadas & 14 & $82,35 \%$ \\
\hline Ajustes de exercícios anteriores & 13 & $76,47 \%$ \\
\hline Ônus, garantias e responsabilidades & 13 & $76,47 \%$ \\
\hline Retenção de lucro & 13 & $76,47 \%$ \\
\hline Ações em tesouraria & 11 & $64,71 \%$ \\
\hline Equivalência patrimonial & 11 & $64,71 \%$ \\
\hline Remuneração dos administradores & 10 & $58,82 \%$ \\
\hline Capital autorizado & 9 & $52,94 \%$ \\
\hline Investimentos societários no exterior & 8 & $47,06 \%$ \\
\hline Dividendo por ação & 5 & $29,41 \%$ \\
\hline Eventos subseqüentes & 3 & $17,65 \%$ \\
\hline Opções de compra de ações & 2 & $11,76 \%$ \\
\hline Reserva de lucros realizada e a realizar & 2 & $11,76 \%$ \\
\hline Arrendamento mercantil & 1 & $5,88 \%$ \\
\hline \multicolumn{1}{|c|}{ Informações Obrigatórias no RA } & fi & fi\% \\
\hline Aquisição de debêntures de própria emissão & 3 & $7,65 \%$ \\
\hline $\begin{array}{l}\text { Disposições sobre a política de reinvestimento de lucros e distribuição de } \\
\text { dividendos }\end{array}$ & 10 & $58,82 \%$ \\
\hline Relacãao dos investimentos em sociedades coligadas e/ou controladas e as \\
modificaçoses ocorridas durante o exercicio
\end{tabular}

Fonte: elaborado pelos autores. 
Especificamente em relação às informações obrigatórias divulgadas nas NE, observa-se significativa variação da frequência entre as 17 companhias analisadas. De acordo com os itens listados no parâmetro de divulgação, apenas as informações sobre - Capital Social e os Critérios de Avaliação são divulgadas por todas as companhias. As Mudanças de Critérios Contábil, Reservas e Demonstrações Consolidadas também são informações significativamente divulgadas, mas não pela totalidade das companhias.

Por outro lado, Arrendamento Mercantil e Opções de Compra de Ações são as informações menos divulgadas. Esse fato pode ser justificado, em parte, pela não ocorrência de transações relacionadas a esses itens na maioria das companhias analisadas. Entretanto, para outras informações obrigatórias, tais como Dividendo por Ação e Remuneração dos Administradores, observa-se efetiva omissão das companhias.

Para as informações obrigatórias divulgadas no RA, a variação é ainda mais discrepante. Informações sobre a Aquisição de Debêntures foi a menos divulgada; presume-se ser decorrente da não ocorrência de transações relacionadas a debêntures na maioria das companhias analisadas. Informações em relação às Disposições sobre a política de Reinvestimento de Lucros e Distribuição de Dividendos são divulgadas por 10 companhias. Em geral, poucas companhias divulgaram as informações obrigatórias no RA. A frequência relativa máxima foi de $58,82 \%$ para o item Política de Reinvestimento de Lucros e Distribuição de Dividendos.

As companhias têm omitido certas informações obrigatórias para o mercado de ações brasileiro. A análise das NE nas companhias da amostra demonstra mais enfaticamente que as companhias se preocuparam pouco com as necessidades informacionais dos diferentes usuários da Contabilidade.

De acordo com o pressuposto de que as informações obrigatórias têm foco especificamente no usuário investidor, aliado ao fato dessas informações não terem sido apresentadas em sua totalidade, pôde-se perceber que as 17 companhias não apresentaram as informações suficientes para o seu principal usuário - investidor.

Posteriormente à análise dos itens obrigatórios, na Tabela 2, apresentam-se as divulgações das informações voluntárias destinadas a usuários específicos e as voluntárias adicionais nas NE e no RA. Acerca das informações voluntárias destinadas a usuários específicos, observa-se que poucas companhias divulgam informações voluntárias destinadas a usuários específicos.

As informações sobre Dividendos Propostos pela Administração e os Relatórios sobre Ações Judiciais Importantes foram os itens mais divulgados, respectivamente $58,82 \%$ e $52,94 \%$ das companhias apresentam essas informações nas NE. O Balanço Social; as informações sobre o Número de Funcionários e Turnover e os Projetos Sociais não foram apresentadas. 
Tabela 2: Informações voluntárias destinadas a usuários específicos divulgadas

\begin{tabular}{|c|c|c|c|}
\hline & Informações voluntárias destinadas a usuários específicos & fi & $f i \%$ \\
\hline \multirow{5}{*}{$\mathbf{z}$} & Balanço social & - & - \\
\hline & $N^{\circ}$ de empregados, turnover & - & - \\
\hline & Projetos sociais & - & - \\
\hline & Relatório sobre ações judiciais importantes & 9 & $52,94 \%$ \\
\hline & Dividendos propostos pela Administração & 10 & $58,82 \%$ \\
\hline \multirow[t]{2}{*}{$\S$} & Descrição de reorganização societária & 2 & $11,76 \%$ \\
\hline & Informações voluntárias adicionais & fi & fi\% \\
\hline \multirow{6}{*}{ 亗 } & Descrição dos negócios da companhia & 17 & $100,00 \%$ \\
\hline & Nota sobre Ativos Segurados & 15 & $88,24 \%$ \\
\hline & Maior ênfase nas demonstrações consolidadas & 14 & $82,35 \%$ \\
\hline & Comentários sobre a conjuntura econômica & 10 & $58,82 \%$ \\
\hline & Notas sobre resultados por linha de produtos ou segmentos de negócios & 2 & $11,76 \%$ \\
\hline & Descrição sucinta de projetos de P\&D e os recursos alocados nesses & - & - \\
\hline \multirow{4}{*}{$\$$} & $\begin{array}{l}\text { Discusssão e análise da situação financeira e dos resultados operacionais pela } \\
\text { Administração }\end{array}$ & 12 & $70,59 \%$ \\
\hline & Mercado de ações da companhia & 8 & $47,06 \%$ \\
\hline & Descrição e objetivos dos investimentos & 3 & $17,65 \%$ \\
\hline & Descrição de novos produtos e as expectativas & 2 & $11,76 \%$ \\
\hline
\end{tabular}

Fonte: elaborado pelos autores

Em relação às informações voluntárias destinadas a usuários específicos evidenciadas no RA, apenas a Usiminas e Vicunha divulgaram dados sobre a descrição de reorganização societária. Essa omissão das informações não compulsórias, tanto nas NE quanto nos RA, pode estar relacionada ao pressuposto de que, para a divulgação das informações, considera-se que as necessidades informacionais dos diferentes usuários da informação são satisfeitas, por meio das informações divulgadas com foco apenas nos investidores e acionistas, ou seja, com base nas informações obrigatórias.

Das companhias analisadas, excetuando-se as duas empresas do Grupo Gerdau, todas as demais 15 companhias apresentam Notas sobre Ativos Segurados. Apesar disso, todas elas divulgaram informações sobre a Descrição dos Negócios. Em relação à apresentação de Comentários sobre a Conjuntura Econômica, a maioria das companhias $(58,82 \%)$ evidenciou essas informações nas NE. Além disso, 14 companhias - 82,35\%, também dão maior ênfase nas Demonstrações Consolidadas. No que se refere aos itens divulgados no RA, a frequência de informações divulgadas pelas companhias é significativamente menor. Para as informações voluntárias adicionais que poderiam ser evidenciadas nesse relatório, apenas a Discussão e a Análise da Situação Financeira e dos Resultados Operacionais pela Administração são apresentadas pela maioria delas $(70,59 \%)$.

Pode-se observar ainda que nenhuma companhia apresentou informações sobre projetos de P\&D. Apenas a CSN e a Vicunha divulgaram notas sobre resultados por 
linha de produtos ou segmentos de negócio e, somente a CSN e a Usiminas apresentam descrição sobre novos produtos e as expectativas em relação a esses. A Usiminas e as companhias Mangels e Paranapanema, por sua vez, são as únicas que evidenciaram a descrição e os objetivos dos investimentos realizados.

A política de divulgação é fundamental para que a Contabilidade atenda seus objetivos de gerar informações para todos os seus usuários, não se restringindo apenas a publicação das demonstrações contábeis obrigatórias, mas se estendendo também a outros aspectos relativos a companhia que possam influenciar na tomada de decisão (LOPES; MARTINS, 2007). A assimetria informacional é um dos motivos para que o custo de capital para a empresa seja maior. Para Nossa (2002), Lima (2007) e Mazer (2007, uma maneira de resolver o problema seria aumentar o disclosere. A conseqüente diminuição de custos daí resultante deve-se à presunção de que quanto mais a empresa se comunica com o mercado, mais se aumenta a liquidez das ações e a cobertura por parte dos analistas de mercado. Isso porque,pó, com o volume maior de informações, diminuem-se os riscos para os stakeholders.

Lambert, Leuz e Verrecchia (2007) esclarecem que a qualidade das informações contábeis influenciam no custo de capital de uma empresa, tanto diretamente quanto indiretamente. Diretamente, pela mudança do mercado decorrente das percepções dos participantes sobre a distribuição de fluxos de caixa futuros. Indiretamente, por afetar decisões internas da empresa sobre a distribuição de fluxos de caixa futuros.

\subsection{DESCRIÇÃO E ANÁLISE DOS DADOS A PARTIR DE MÉTRICAS QUANTITATIVAS}

Após verificar quais itens obrigatórios e voluntários (específicos e adicionais) são divulgados pelas 17 companhias do subsetor siderurgia e metalurgia da BOVESPA, é possível realizar uma análise da divulgação das informações segundo as métricas quantitativas (definidas no Quadro 4). Na Tabela 3, apresenta-se o resultado dessa análise de acordo com cada companhia. Mostra-se a frequência absoluta (fi) e a relativa (fi\%) das informações obrigatórias divulgadas conjuntamente nas NE e nos RA, assim como para as informações voluntárias específicas e adicionais.

Para análise das informações obrigatórias divulgadas pelas companhias tomou-se como base a descrição das frequências apresentada nas Tabelas 1 e 2 . Em relação às informações obrigatórias, as companhias deveriam divulgar ao todo 24 itens para atingir o índice $100 \%$ de divulgação. A quantidade de itens divulgados pelas companhias individualmente foi dividida pelo total (24 itens), para se obter o percentual (frequência) de divulgação de informações obrigatórias. Conforme se observa, as companhias com os melhores percentuais são Usiminas (92\%), Mangels (79\%), CONFAB (75\%) e Gerdau (75\%).

Com base nesses percentuais, classificou-se as companhias nos três níveis e graus de divulgação. Apenas a Usiminas atingiu o Grau 3, para o Nível Adequado de divulgação. As demais foram classificadas no Grau 2 do Nível Adequado, por atingirem 
entre $40 \%$ a $80 \%$ da divulgação das informações obrigatórias nas NE e nos RA. Destacase ainda que apenas as companhias Aliperti e Duque foram classificadas no Grau 1 do Nível Adequado.

Posteriormente, para a análise das informações voluntárias destinadas a usuários específicos, divulgadas pelas companhias tanto nas NE quanto nos RA, tomouse como base a descrição das frequências apresentada na Tabela 3. Em relação a essas informações (voluntárias específicas), as companhias deveriam divulgar ao todo 6 itens para atingir 100\% de divulgação. Mapeou-se a quantidade de itens divulgados pelas companhias individualmente e dividiu-se pelo total (6 itens) para obter 0 percentual de divulgação específica para determinados usuários.

Tabela 3: Frequência absoluta e relativa de itens divulgados pelas 17 companhias

\begin{tabular}{|c|c|c|c|c|c|c|}
\hline \multirow[t]{2}{*}{ Companhias } & \multicolumn{2}{|c|}{$\begin{array}{l}\text { Informações } \\
\text { obrigatórias }\end{array}$} & \multicolumn{2}{|c|}{$\begin{array}{c}\text { Informações voluntárias } \\
\text { destinadas a usuários } \\
\text { específicos }\end{array}$} & \multicolumn{2}{|c|}{$\begin{array}{l}\text { Informações volun- } \\
\text { tárias adiciona }\end{array}$} \\
\hline & fi & fi\% & fi & fi\% & fi & fi\% \\
\hline Aços Villares & 16 & 67 & 2 & 33 & 6 & 60 \\
\hline Aliperti & 7 & 29 & 0 & 0 & 3 & 30 \\
\hline Caraíba & 15 & 63 & 2 & 33 & 3 & 30 \\
\hline CONFAB & 18 & 75 & 1 & 17 & 5 & 50 \\
\hline CSN & 17 & 71 & 2 & 33 & 8 & 80 \\
\hline Duque & 5 & 21 & 0 & 0 & 2 & 20 \\
\hline ELUMA & 14 & 58 & 1 & 17 & 5 & 50 \\
\hline FERBASA & 12 & 50 & 1 & 17 & 4 & 40 \\
\hline FIBAM & 11 & 46 & 1 & 17 & 5 & 50 \\
\hline Gerdau & 18 & 75 & 2 & 33 & 5 & 50 \\
\hline Gerdau Metalúgica & 17 & 71 & 0 & 0 & 4 & 40 \\
\hline Mangels & 19 & 79 & 1 & 17 & 7 & 70 \\
\hline Panatlântica & 12 & 50 & 0 & 0 & 3 & 30 \\
\hline Paranapanema & 15 & 63 & 1 & 17 & 7 & 70 \\
\hline Tekno & 17 & 71 & 1 & 17 & 3 & 30 \\
\hline Usiminas & 22 & 92 & 3 & 50 & 8 & 80 \\
\hline Vicunha & 17 & 71 & 3 & 50 & 5 & 50 \\
\hline
\end{tabular}

Fonte: elaborado pelos autores.

Considerando a hierarquização e a progressão dos níveis de divulgação, a companhia somente poderia migrar do Nível Adequado para, sequencialmente, o Nível Justo se atingisse o Grau 3 desse primeiro nível; e também dessa forma, para o Nível Completo. Assim, somente a Usiminas alcançou o Nível Justo, com Grau 2 por divulgar de 0 a 40\% das informações voluntárias destinadas a usuários específicos. Dos 6 itens exigidos para essas informações, a Usiminas divulgou apenas 3 (50\%), sendo, dessa forma, classificada no Grau 2 do Nível Justo. Nenhuma companhia atingiu no mínimo $80 \%$ de divulgação das informações obrigatórias (Nível Justo) e $80 \%$ de divulgação das informações voluntárias específicas para determinados usuários para ser classificada no Nível Completo de Grau 3. 
Choi e Meek (2004) explicam que o crescimento da importância do mercado de capitais nas economias nacionais torna os investidores individuais mais ativos nesses mercados, aumentando a importância dos padrões de governança corporativa e influenciando fortemente as práticas de evidenciação em todo o mundo. Ressaltam que regulações governamentais, com o objetivo de manter ou aumentar a credibilidade de seus mercados de capitais nacionais, também influenciam as práticas de divulgação financeira.

$\mathrm{Na}$ medida em que os investidores demandam informações mais detalhadas e oportunas, a evidenciação voluntária tenda a aumentar em mercados desenvolvidos e emergentes. Porém, ainda prevalecerá diferenças entre o grau de evidenciação de empresas pertencentes ao mesmo mercado. Isso pode ser parcialmente explicado pelos incentivos dos administradores para divulgar tempestiva e detalhadamente informações sobre os negócios. As desvantagens competitivas oriundas da divulgação de informações sobre os negócios da empresa podem superar os benefícios da evidenciação completa.

\section{CONCLUSÕES E RECOMENDAÇÕES}

Considerando-se as necessidades informacionais dos diferentes usuários da informação, bem como o elevado número de transações realizadas atualmente no mercado de ações, parece pertinente afirmar que quaisquer informações que possam interferir ou influenciar no processo de tomada de decisões racionais devam ser divulgadas aos usuários interessados. Nesse sentido, o objetivo do presente estudo foi analisar o nível de divulgação de informações de companhias brasileiras do subsetor de siderurgia e metalurgia com ações negociadas na BOVESPA.

A análise do nível de disclosure teve como base a quantidade de informações divulgadas. No Nível Adequado, o enfoque da divulgação foi sobre as informações obrigatórias. No Nível Justo, além das informações adequadas, a divulgação precisou atender as necessidades informacionais de grupos de usuários distintos, tais como: investidores, credores, funcionários e governo. No Nível Completo, além das informações adequadas e justas, a divulgação deveria contemplar as informações voluntárias.

Para a diferenciação dos graus de divulgação utilizaram-se os critérios qualitativos e métricas quantitativas, definidas por meio de uma Escala Likert. A partir disto, as divulgações das companhias puderam ser enquadradas nos diferentes níveis de divulgação em diferentes graus, de acordo com a quantidade de informações evidenciadas. Os resultados mostram que apenas a companhia Usiminas obteve percentual suficiente para ser considerada no Nível Justo no Grau 2. As demais companhias analisadas foram classificadas no Grau 2 do Nível Adequado e apenas 2 delas (Aliperti e Duque) classificadas no Grau 1 do Nível Adequado.

Em relação às informações voluntárias, destaca-se que o Balanço Social, não foi apresentado por nenhuma companhia do subsetor analisado, inclusive pela Usiminas. Além disso, poucas companhias divulgaram nas NE informações sobre as 
ações judiciais importantes e sobre os dividendos propostos pela Administração. No RA, apenas Usiminas e Vicunha divulgaram informações sobre a descrição de reorganização societária.

Apesar da importância e do volume de transações realizadas no subsetor siderurgia e metalurgia, nenhuma companhia atingiu o Nível Completo. Tal como observado nas NE, as companhias têm omitido certas informações obrigatórias, fato que é preocupante para o mercado de ações brasileiro. A análise das NE demonstra mais enfaticamente que as companhias se preocuparam pouco com as necessidades informacionais dos diferentes usuários da Contabilidade. Além disso, de acordo com pressuposto de que as informações obrigatórias têm foco especificamente no usuário investidor, e pelo fato de que essas informações não foram apresentadas em sua completude, pode-se intuir que, pelo menos, 16 companhias não apresentaram informações suficientes para o principal usuário das informações contábeis investidor.

Essa realidade pode ser caracterizada como falta de maturidade do mercado acionário brasileiro. Quando as companhias apresentam alto nível de divulgação é possível que um maior número de usuários seja atendido e que os diferentes usuários tenham capacidade de estruturar e desenvolver análises econômico-financeiras, que auxiliem no processo de tomada de decisões racionais e na previsão de crescimento ou decréscimo do mercado. Disponibilizar as informações que os usuários necessitam é um dos objetivos principais da Contabilidade, fato que não se observa no subsetor analisado.

Num contexto mundial, em que se procura ampliar os mercados de capitais, a constatação de que apenas 1 companhia, dentre as 17 analisadas, pôde ser considerada como no Nível Justo de divulgação de informações, demonstra a necessidade das companhias aprimorarem seu processo de evidenciação, bem como de definir o efetivo objetivo das informações divulgadas. Considera-se que o nível de divulgação pode ser relacionado ao grau de segurança de o investidor comprar/vender ações de determinada companhia. Ou seja, ao analisar as informações contábeis divulgadas, esse usuário pode desenvolver análises que possibilite a realização de inferências e a construção de perspectivas sobre o investimento. Assim, pela análise realizada, podese concluir que o delineamento dos critérios qualitativos para a avaliação do nível de disclosure das informações de companhias brasileiras foi adequado e possibilita a classificação e diferenciação das empresas analisadas.

Segundo Hendriksen e Van Breda (1999), a busca pela satisfação das necessidades informacionais dos diferentes grupos de usuários relaciona-se diretamente ao alcance das necessidades informacionais dos investidores e acionistas. Quanto maior a quantidade e a qualidade das informações apresentadas nas NE e nos RA, maior a possibilidade dos usuários secundários serem atendidos. Consequentemente, melhores são as chances de se obter a maturidade do mercado de ações brasileiro.

Constatou-se que, segundo os critérios qualitativos definidos, as companhias estão incipientes na divulgação de informações obrigatórias e voluntárias, uma vez que não divulgam informações em quantidade suficientes aos usuários. Estudos posteriores podem objetivar a análise qualitativa, mas nesse estudou se considerou a possibilidade de que a quantidade da informação seria uma abordagem de avaliação 
do nível de divulgação praticado pelas companhias brasileiras. Acredita-se que o delineamento dos critérios para a avaliação do nível de disclosure das informações de companhias brasileiras, embora considerado adequado e possibilite a classificação e diferenciação das empresas analisadas, ainda padece de mecanismos que possam compreender o fenômeno do baixo nível de disclosure de empresas brasileiras.

\section{REFERÊNCIAS}

AL-SHAMMARI, Bader A. Compliance with International Accounting Standards by Listed Companies in the Gulf Co-operation Council Member States: an empirical study. Thesis (Doctor of Philosophy). UWA Business School of The University of Western Australia. Australia, 2005..

ALENCAR, Roberta Carvalho de. Nível de Disclosure e Custo de Capital Próprio no Mercado Brasileiro. Tese (Doutorado em Ciências Contábeis). Departamento de Contabilidade e Atuária da Faculdade de Economia, Administração e Contabilidade da Universidade de São Paulo. São Paulo, 2007.

ALVES, C. V. O.; LIMA, G. A. S. F. Reputação corporativa e nível de disclosure das empresas de capital aberto no Brasil. In: CONGRESSO USP CONTROLADORIA E CONTABILIDADE, 8, 2008, São Paulo. Anais... São Paulo: USP, 2008.

BARDIN, L. Análise de conteúdo. 2.ed. Lisboa: Edições 70, 2002.

BOVESPA, Bolsa de Valores de São Paulo. Classificação do setor de atuação das companhias. Disponível em: <http://www.bovespa.com.br/Principal.asp>. Acesso em: 26 mai. 2009.

BRISOLA, J. Teoria do agenciamento na contabilidade: a contabilidade e o processo de comunicação. ConTexto, Porto Alegre, v. 4, n.7, $2^{\circ}$ sem., 2004. Disponível em: <http://www.ufrgs.br/necon/n7>. Acesso em: 26 mai 2009.

BUENO, A. F. Problemas de disclosure no Brasil: o caso das empresas com ações no exterior. Caderno de Estudos. São Paulo, FIPECAFI, n. 20, jan./abr. 1999.

CVM, Comissão de Valores Mobiliários. Pareceres Jurídicos de 1978 a 2001. Disponível em: <http://www.cvm.gov.br/indexpo.asp>. Acesso em: 22 mai. 2009.

CHOI, Frederick S; MEEK, Gary K. International Accounting. Prentice Hall, 5 ed. 2004.

FERREIRA, V. F.; BOTELHO, D. R. Análise do nível de evidenciação dos itens compulsórios e não compulsórios: um estudo nos relatórios contábeis da Petrobrás. In: CONGRESSO DA USP DE INICIAÇÃO CIENTÍFICA EM CONTABILIDADE, 3, 2006, São Paulo. Anais... São Paulo: USP, 2006.

GONÇALVES, O.; OTT, E. A evidenciação nas companhias brasileiras de capital aberto. In: ENCONTRO NACIONAL DA ANPAD (ENANPAD), 26, 2002, Salvador. Anais... Salvador, 
2002.

GONÇALVES, R. S.; WEFFORT, E. F. J.; PELEIAS, I. R.; GONÇALVES, A. O. Proposta de construção e aplicação de um índice para avaliação do social disclosure por empresas brasileiras. In: CONGRESSO ANPCONT, 1, 2007, Gramado. Anais... Gramado, 2007.

GOULART, A. M.C. Evidenciação contábil do risco de mercado por instituições financeiras no Brasil. 2003. 202 f. Dissertação (Mestrado em Controladoria e Contabilidade) Faculdade de Economia, Administração e Contabilidade da Universidade Federal de São Paulo (USP), São Paulo, 2003.

GRAHAM, J.R.; HARVEY, C. R.; RAJGOPAL, S. The economic implications of corporate financial reporting. Journal of Accounting Economics, v. 40, pp. 3-73, 2005.

HENDRIKSEN, E. S.; VAN BREDA, M. F. Teoria da contabilidade. São Paulo: Atlas, 1999.

HEALY, P. M.; PALEPU, K. G. Information asymmetry, corporate disclosure, and the capital markets: a review of the empirical disclosure literature. Journal of Accounting and Economics, n. 31, pp. 405-440, 2001.

HIRSHLEIFER, D.; TEOH, S. H. Limited attention, information disclosure, and financial reporting. Journal of Accounting and Economics, n. 36, pp. 337-386, 2003.

HO, L.-C. J.; TAYLOR, M. E. An Empirical Analysis of Triple Bottom-Line Reporting and its Determinants: Evidence from the United States and Japan. Journal of International Financial Management and Accounting, n. 18, pp. 123-150, 2007.

HOPE, O.-K. Firm-level disclousures and the relative roles of culture and legal origin. Journal of International Financial Management and Accounting, n. 14, pp. 218-248, 2003.

LAMBERT, Richard; LEUZ, Christian; VERRECCHIA, Robert E. Accounting Information, Disclosure, and the Cost of Capital. Journal of Accounting Research, v. 45, n. 2, p. 385-420, 2007.

LANZANA, A. P. Relação entre disclosure e governança corporativa das empresas brasileiras. 2004. 165 f. Dissertação (Mestrado em Administração) - Faculdade de Economia, Administração e Contabilidade da Universidade Federal de São Paulo (USP), São Paulo, 2004.

LIMA, Gerlando Augusto Sampaio Franco de. Utilização da Teoria da Divulgação Para Avaliação da Relação do Nível de Disclosure com o Custo da Dívida das Empresas. Tese (Doutorado em Controladoria e Contabilidade). Departamento de Contabilidade e Atuária da Faculdade de Economia, Administração e Contabilidade da Universidade de São Paulo. São Paulo, 2007.

LOPES, A. B.; MARTINS, E. Teoria da contabilidade: uma nova abordagem. São Paulo: Atlas, 2007.

MAZER, Lílian Perobon. O Impacto do Nível de Transparência no Custo do Capital Próprio 
das Empresa do Ibovespa. Dissertação (Mestrado em Controladoria e Contabilidade). Departamento de Contabilidade da Faculdade de Economia, Administração e Contabilidade de Ribeirão Preto da Universidade de São Paulo. Ribeirão Preto, 2007.

MURCIA, Fernando Dal-Ri; SANTOS, Ariovaldo dos. Principais Práticas de Disclosure Voluntário das 100 Maiores Empresas Listadas na Bolsa de Valores de São Paulo. Revista Contabilidade e Controladoria, v. 01, n. 01, p. 61-78, 2009.

NOSSA, Valcemiro. Disclosure Ambiental: uma análise do conteúdo dos relatórios ambientais de empresas do setor de papel e celulose em nível internaiconal. Tese (Doutorado em Controladoria e Contabilidade). Departamento de Contabilidade e Atuária da Faculdade de Economia, Administração e Contabilidade da Universidade de São Paulo. São Paulo, 2002.

PONTE, V. M. R.; OLIVEIRA, M. C.; MOURA, H.; CARMO, R. C. A. Análise das Práticas de Evidenciação de Informações Obrigatórios, Não-Obrigatórias e Avançadas nas Demonstrações Contábeis das Sociedades Anônimas no Brasil: um estudo comparativo dos exercícios de 2002 e 2005. Revista Contabilidade \& Finanças,, v. 18, n. 45, p. 50-62, 2007.

PONTE, V. M. R.; OLIVEIRA, M. C.; MOURA, H.; CARMO, R. C. A. Análise das Práticas de Evidenciação de Informações Obrigatórios, Não-Obrigatórias e Avançadas nas Demonstrações Contábeis das Sociedades Anônimas no Brasil: um estudo comparativo dos exercícios de 2002 e 2005. Revista Contabilidade \& Finanças, , v. 18, n. 45, p. 50-62, 2007.

PONTE, V. M. R.; OLIVEIRA, M. C.; MOURA, H.; CARMO, R. C. A. Análise das práticas de evidenciação de informações obrigatórios, não-obrigatórias e avançadas nas demonstrações contábeis das sociedades anônimas no Brasil: um estudo comparativo dos exercícios de 2002 e 2005. Revista Contabilidade \& Finanças FIPECAFI - FEA USP. São Paulo, v. 18, n. 45, p. 50-62, setembro/dezembro 2007.

SALOTTI, B. M.; YAMAMOTO, M. M. Divulgação voluntária da Demonstração dos Fluxos de Caixa no mercado de capitais brasileiro. In: ENCONTRO NACIONAL DA ANPAD (EnANPAD), 30, 2006, Salvador. Anais... Salvador, 2006.

SAMPIERI, R. H.; COLLADO, C. F.; LUCIO, P. B. Metodologia de pesquisa. 3. ed. São Paulo: McGraw Hill, 2006.

VASCONCELOS, Y. L.; VIANA, A. L. Evidenciação: forma e qualidade. Revista do Conselho Federal de Contabilidade. n. 134, p. 21-29, março/abril 2002.

YAMAMOTO, M. M.; SALOTTI, B. M. Informação contábil: estudos sobre a sua divulgação no mercado de capitais. São Paulo: Atlas, 2006. 


\section{ENDEREÇO DOS AUTORES:}

Eduardo Mendes Nascimento

Universidade Federal de Minas Gerais, Faculdade de Ciências Econômicas

Departamento de Ciências Contábeis

Av Antônio Carlos n 6627 - Pampulha

Belo Horizonte, MG - Brasil

$31270-901$

Mariana Guerra

Universidade Federal de Minas Gerais

Avenida Alfredo Balena, 110 - Santa Efigência

Belo Horizonte, MG - Brasil

$30130-100$

Nirlene Aparecida Carneiro Fernandes

Universidade Federal de Minas Gerais, Faculdade de Ciências Econômicas

Avenida Antônio Carlos, 6627

Belo Horizonte, MG - Brasil

$30130-100$

Romualdo Douglas Colauto

Universidade Federal do Paraná

Setor de Ciências Sociais Aplicadas

Av. Prefeito Lothário Meissner, 632 - Campus III

Jardim Botânico - Curitiba, PR - Brasil

80210-070 